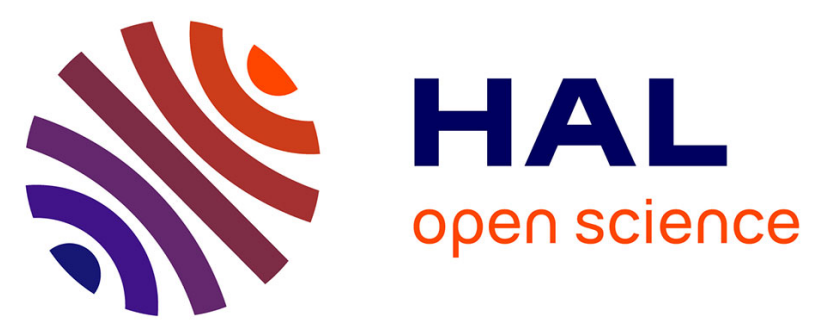

\title{
Tuning Mesoporous Silica Films Accessibility Through Controlled Dissolution in NH 4 F: Investigation of Structural Change by Ellipsometry Porosimetry and X-ray Reflectivity
}

\author{
Jérôme Loizillon, Magali Putero, David Grosso
}

\section{To cite this version:}

Jérôme Loizillon, Magali Putero, David Grosso. Tuning Mesoporous Silica Films Accessibility Through Controlled Dissolution in NH 4 F: Investigation of Structural Change by Ellipsometry Porosimetry and X-ray Reflectivity. Journal of Physical Chemistry C, 2019, 123 (50), pp.30398-30406. 10.1021/acs.jpcc.9b09109 . hal-02903109

\section{HAL Id: hal-02903109 \\ https://hal.science/hal-02903109}

Submitted on $20 \mathrm{Jul} 2020$

HAL is a multi-disciplinary open access archive for the deposit and dissemination of scientific research documents, whether they are published or not. The documents may come from teaching and research institutions in France or abroad, or from public or private research centers.
L'archive ouverte pluridisciplinaire HAL, est destinée au dépôt et à la diffusion de documents scientifiques de niveau recherche, publiés ou non, émanant des établissements d'enseignement et de recherche français ou étrangers, des laboratoires publics ou privés. 


\section{C: Surfaces, Interfaces, Porous Materials, and Catalysis}

\section{Tuning Mesoporous Silica Films Accessibility Through Controlled Dissolution in NHF: Investigation of Structural Change by Ellipsometry Porosimetry and X-ray Reflectivity Jérôme Loizillon, Magali Putero, and David Grosso}

J. Phys. Chem. C, Just Accepted Manuscript • DOI: 10.1021/acs.jpcc.9b09109 • Publication Date (Web): 19 Nov 2019

Downloaded from pubs.acs.org on November 25, 2019

\section{Just Accepted}

"Just Accepted" manuscripts have been peer-reviewed and accepted for publication. They are posted online prior to technical editing, formatting for publication and author proofing. The American Chemical Society provides "Just Accepted" as a service to the research community to expedite the dissemination of scientific material as soon as possible after acceptance. "Just Accepted" manuscripts appear in full in PDF format accompanied by an HTML abstract. "Just Accepted" manuscripts have been fully peer reviewed, but should not be considered the official version of record. They are citable by the Digital Object Identifier (DOI®). "Just Accepted" is an optional service offered to authors. Therefore, the "Just Accepted" Web site may not include all articles that will be published in the journal. After a manuscript is technically edited and formatted, it will be removed from the "Just Accepted" Web site and published as an ASAP article. Note that technical editing may introduce minor changes to the manuscript text and/or graphics which could affect content, and all legal disclaimers and ethical guidelines that apply to the journal pertain. ACS cannot be held responsible for errors or consequences arising from the use of information contained in these "Just Accepted" manuscripts. 


\section{Tuning Mesoporous Silica Films Accessibility Through Controlled Dissolution in $\mathrm{NH}_{4} \mathrm{~F}$ : Investigation of Structural Change by Ellipsometry Porosimetry and X-ray Reflectivity}

\section{Jérôme Loizillon ${ }^{1}$, Magali Putero ${ }^{1}$ and David Grosso ${ }^{1 *}$}

1 Institut Matériaux Microélectronique et Nanosciences de Provence, (IM2NP) - UMR CNRS 7334, Aix-Marseille Université, Faculté des Sciences de Saint Jérôme, 13397 Marseille Cedex 20, France

E-mail : david.grosso@univ-amu.fr

\section{ABSTRACT}

In this work, we present a method to accurately increase the porosity of mesoporous silica films using a post-synthesis controlled partial dissolution in dilute $\mathrm{NH}_{4} \mathrm{~F}$ aqueous solutions. This investigation was performed on around $100 \mathrm{~nm}$ thick films prepared by sol-gel chemistry and evaporation-induced self-assembly with various classical micellar templating agents. The evolution of the pore size, the pore interconnection size, the pore organization and the film thickness were followed by ellipsometry porosimetry and $\mathrm{x}$-ray reflectivity along the dissolution process. We show that the dissolution always proceeds in two well-distinct steps. First the dissolution provokes the increase of the pore volume, with increasing pore and interconnection sizes, without modification of the structure and the thickness. Then, the collapse of the porous network leads to the reduction of the porosity and the thickness, confirming that a critical maximal porosity can be obtained with each of these systems. The dissolution kinetics, studied in different conditions of chemical attack, revealed that the dissolution follows a linear tendency in each case, facilitating the control over the porosity tuning. Finally, a mechanism for sol-gel based mesoporous silica dissolution mechanism is proposed. Overall, a convenient method to increase the pore size without damaging the pore structure is proposed.

\section{INTRODUCTION}

Controlling the porosity in materials is needed for a large span of applications that require control of molecular diffusion, or adjustment of adsorption/desorption equilibria, or a simple modification of physical-chemical properties (density, surface area, optical index...) for instance. To go further, such a porosity can be further infiltrated with an additional material of interest (e.g. metals, metal oxides or polymers) to create controlled nanocomposites systems for sensing, heterogenous catalysis, energy harvesting, and many other applications. Concerning coating, tuning the porosity of inorganic metal oxide films can first be obtained by controlling parameters that govern evaporation-induced-self-assembly during sol-gel processing (type of templating 
agent, micelle size and morphology, micelle arrangement, micelle concentration). Unfortunately, most of the time, this method does not lead to highly accessible porosity required for infiltration. This was confirmed through typical examples of silica films modification through infiltration reported with polymers, ${ }^{1}$ metal oxides $\left(\mathrm{SnO}_{2}{ }^{2}\right.$ or $\left.\mathrm{ZnO}^{3}\right)$ or gold nanoparticles. ${ }^{4}$ Besides, capillary infiltration phenomena have also been studied ${ }^{5,6}$ and applied to elaborate new materials for bone tissue engineering, ${ }^{7}$ sensors ${ }^{8}$ and photovoltaic applications. ${ }^{9}$ Each example confirmed that a fine tuning of interconnections in the porous network is required.

In this work, the modification of the mesoporosity in silica coatings was performed by controlled dissolution in $\mathrm{NH}_{4} \mathrm{~F}$ solution. The study of silica dissolution using various acids has been done in the literature. ${ }^{10,11}$ It was shown that dissolution can lead to recondensation of dissolved species on the silica matrix, resulting in non-uniform increase of the porosity. On the contrary, using fluoride species, silica is ultimately converted into $\mathrm{SiF}_{6}{ }^{2-}$ ions which are stable and won't recondense on the silica matrix. The study of silica dissolution by fluorides has been studied in the literature by Kobayashi and coworkers ${ }^{12}$ and the kinetics of the reactions were detailed by Osseo-Asare and coworkers. ${ }^{13}$ Additionally, Minhao and coworkers followed the etching evolution of thin silica films by $\mathrm{XRR}^{14}$ and compared the dissolution rate of plain silica films with that of mesoporous ones in basic media. They revealed that it proceeds in well-defined stages depending on the degree of condensation, and on the porosity. This study was conducted with $\mathrm{NaOH}$ as chemical reactant. In such alkaline conditions, silica is known to evolve following an Ostwald's ripening mechanism, through which a dissolution/recondensation equilibrium is maintained all along the efficient attack period. In this work we present a complementary study, where sodium hydroxide is replaced by fluoride reactant to avoid the silica recondensation. Furthermore, ellipsometry porosimetry (EP) and x-ray reflectivity (XRR) were combined to assess as much as possible the real porous structure necessary to propose a supported mechanism. We revealed that the evolution of the porous network occurs in two successive and distinct steps: a first one in which the pore volume and the accessibility simultaneously increase without modification of the structure and the thickness. It is followed by a second step where the film collapses creating a loss of porosity, structure and consequently thickness. A mechanism of chemical attack is proposed based on the systematic investigations of dissolution kinetics in different concentrations of $\mathrm{NH}_{4} \mathrm{~F}$. Finally, we showed that hybrid hydrophobic silica coatings are not affected by the dissolution.

\section{EXPERIMENTAL SECTION}

\section{Elaboration of Coatings}

Silica coatings were elaborated from sol-gel method using Tetraethyl orthosilicate (TEOS) as silica source and Cetyltrimethylammonium tetrachloride (CTAB) and Pluronics F127 as templates. Solution $\mathrm{S}_{\mathrm{F}}$ containing molar ratios of $1 \mathrm{TEOS} / 38 \mathrm{EtOH} / 5 \mathrm{H}_{2} \mathrm{O} / 0.017 \mathrm{HCl} / 2.5 .10^{-3} \mathrm{~F} 127$, solution $\mathrm{S}_{\mathrm{C}}$ containing molar ratio of $1 \mathrm{TEOS} / 10 \mathrm{EtOH} / 5 \mathrm{H}_{2} \mathrm{O} / 0.05 \mathrm{HCl} / 0.05 \mathrm{CTAB}$, hydrophobic silica 
precursor solution $\mathrm{S}_{\mathrm{M}}$ containing molar ratio of $0.5 \mathrm{TEOS} / 0.5 \mathrm{MTEOS} / 10 \mathrm{EtOH} / 5 \mathrm{H}_{2} \mathrm{O} / 0.05 \mathrm{HCl}$ / $2.10^{-3} \mathrm{~F} 127$ and dense silica precursor solution $\mathrm{S}_{\mathrm{D}}$ containing molar ratios of $1 \mathrm{TEOS} / 10 \mathrm{EtOH} /$ $5 \mathrm{H}_{2} \mathrm{O} / 0.05 \mathrm{HCl} / 5.10^{-5} \mathrm{~F} 127$ were prepared and aged $30 \mathrm{~min}$ at $70{ }^{\circ} \mathrm{C}$ before being used for coating. The low quantity of F127 in solution D was used to improve the wetting of the solution without increasing the porosity of the final film. The solutions were deposited onto pre-cleaned silicon wafers by dip-coating (using ACEdip from Solgelway) in the draining regime. Film $\mathrm{F}$ was elaborated from sol $\mathrm{S}_{\mathrm{F}}$ at a withdrawal speed of $5 \mathrm{~mm} \cdot \mathrm{s}^{-1}$ under $50 \% \mathrm{RH}$ followed by $5 \mathrm{~min}$ stabilization to favorize the evaporation-induced self-assembly ${ }^{15}$ of the micelles into periodic arrays. Films $C, D$ and $M$ were elaborated from solution $S_{C}, S_{D}$ and $S_{M}$, respectively, at a withdrawal speed of $4 \mathrm{~mm} . \mathrm{s}^{-1}$ under $\mathrm{RH}<5 \%$ without stabilization. All films were then annealed at $450^{\circ} \mathrm{C}$ for $10 \mathrm{~min}$ under IR lamps. All coatings covered a surface of $50 \times 15 \mathrm{~mm}^{2}$. In the present chemical conditions, the silica network is known to be amorphous and slightly microporous. ${ }^{16}$

Chemical attack of the coatings was performed in $250 \mathrm{ml}$ of $50 \mathrm{mM}, 5 \mathrm{mM}$ and $200 \mathrm{mM} \mathrm{NH}_{4} \mathrm{~F}$ solutions. A single film was used to obtain the whole kinetics of dissolution. To do so, each film was immersed in the fluoride solution and dragged out at a slow speed (e.g. 1-100 $\mu \mathrm{m} . \mathrm{s}^{-1}$ ) in a vertical translation using a dip-coater. In such a configuration, the bottom of the film stayed for a longer time in the solution than the top of the film. The full history of dissolution can thus be read on the same sample between the top and the bottom of the coating, corresponding to a typical distance of $50 \mathrm{~mm}$ in the present cases. A fresh solution was used for each dissolution. New films were elaborated in the same conditions for the ellipsometry porosimetry and XRR analyses, as the latters required a relatively larger surface of analysis. The ellipsometric data between these new films and the corresponding zones of the original sample were in good accordance, showing that the process is repeatable and the data can be compared.

\section{Characterizations and Calculations}

Coating characterizations were performed by Spectroscopic ellipsometry (UV-visible variable angle spectroscopic ellipsometer M2000 Woollam) equipped with a controlled atmospheric cell. Refractive index dispersions and film thicknesses were extracted from conventional $\Psi$ and $\Delta$ fitting (where $\Psi$ and $\Delta$ are the ratio of the amplitude variation and the phase difference induced by the reflection) using a Cauchy model (CompleteEASE software) and measured under dry atmosphere (relative humidity $<5 \%$ using SHT25 from Sensirion) to make sure water is not adsorbed. The porosities were calculated from the refractive index of the coatings using Bruggeman effective medium approximation. The etched samples presenting a gradient of dissolution were analyzed using a micro screw with a $0.5 \mathrm{~mm}$ step between each analysis. The ellipsometer was equipped with focus probes which reduce the size of the analyzed area to 300 $\mu \mathrm{m}^{2}$.

To evaluate the etching rates all along the dissolution, the evolution of the volume of silica for 1 $\mathrm{cm}^{2}$ of coating surface was considered, using the following relation: 


$$
V_{\text {material }}=\left(1-\frac{P}{100}\right) h
$$

Where $P$ and $h$ are the porosity and thickness $(\mathrm{cm})$ of the coating, respectively, and $V_{\text {material }}$ is expressed in $\mathrm{cm}^{3} \cdot \mathrm{cm}^{-2}$. The difference between the initial volume, noted $V_{0}$, and the residual volume after etching time $t$, noted $V_{i}$, gives the term $\Delta V$. The instantaneous etching rate $v_{\text {etch }}$ can then be obtained graphically by plotting $d(\Delta V) / d t$ as a function of etching time $t$. In conditions where the etching time is constant, it can be deduced by linear regression applied on $d(\Delta V)$ vs. $t$.

Water isotherms were obtained from EP investigations performed on the films just after desorption at $150^{\circ} \mathrm{C}$ overnight and 1 min exposition to high $\mathrm{RH}$ to create silanol groups on the wall surface and allow water chemisorption. ${ }^{16}$ The $\mathrm{H}_{2} \mathrm{O}$ relative vapor pressure was adjusted using mass flow controller systems (ACE-flow from Solgelway) and measured directly in the chamber with a sensor. The flux was set at $5 \mathrm{~L} \cdot \mathrm{min}^{-1}$ and each isotherm was recorded in $30 \mathrm{~min}$.

Pore and interconnection size distributions were calculated from the water isotherms using a modified Kelvin equation fully described in the literature. ${ }^{9}$ As a reminder, the Kelvin radius $r_{k}$ was calculated using the following equation:

$$
r_{k}=\mathrm{G}\left(\frac{-\gamma_{0} V_{m o l} \cos \theta}{R T \ln \left(\frac{p}{p_{0}}\right)}+\delta\right)
$$

With $\gamma_{0}=0.072 \mathrm{~N} \cdot \mathrm{m}^{-1}$ the surface tension of water on a flat surface, $\delta=9.6 .10^{-11} \mathrm{~m}$ the bond length of a water molecule, $\theta=24^{\circ}$ the macroscopic water-silica contact angle, $V_{m o l}=18.10^{-6} \mathrm{~m}^{3} \cdot \mathrm{mol}^{-1}$ the water molar volume, $R=8.314 \mathrm{~J} . \mathrm{mol}^{-1} \mathrm{~K}^{-1}$ the gas constant and $T=298 \mathrm{~K}$. Since the shape of the pores was not determined for this study, the assumption was made that pores have an ellipsoidal shape with an anisotropy of 1.5 , similar to what is found in the literature for silica films thermally treated at $450^{\circ} \mathrm{C} .{ }^{16}$ This corresponds to a $G$ value of 1.57 , which was used for both the adsorption and desorption branches.

Then, the pore size was obtained with the following equation:

$$
d_{\text {pore }}=2\left(r_{k}+h_{r e f}\right)
$$

With $h_{\text {ref }}$ the reference thickness of an adsorbed layer of water on a flat surface as a function of the partial pressure $p / p_{0}$ extracted from the literature. ${ }^{17,18}$

XRR patterns were recorded in controlled atmosphere (relative humidity $<10 \%$ ), on a conventional diffractometer (PANalytical Empyrean) using $\mathrm{Cu}$ radiation $(\lambda=0.154 \mathrm{~nm}$ ), programmable divergent slit and anti-scatter slit of $1 / 32^{\circ}$, a rapid detector (PANalytical PIXcel) used in mode receiving slit $(0.16 \mathrm{~mm})$ and equipped with Soller slits $(0.04 \mathrm{rad})$. Specular $\theta-2 \theta$ scans were performed with $\theta$ range $\left[0.1^{\circ}-1^{\circ}\right]$, a step of $0.002^{\circ}$, and a counting time of $4 \mathrm{~s} /$ step. To 
extract the pore dimension, periodicity, the layer thickness and the average density profile along $\mathrm{z}$, the XRR patterns were fitted using the matrix formalis ${ }^{19}$, based on methodologies proposed by Dourdain and coworkers ${ }^{20}$, and an idealized stack model (shown on SI): films were considered to be made of a multilayer stack consisting in a top layer of high density silica over a stack of bilayers repeated $\mathrm{N}=14$ times. Each bi-layer is composed of a bottom layer 1 composed of high density silica (corresponding to the dense silica between the mesopores planes), and a top layer 2 composed of low density mesoporous silica. Layer 1 (resp. 2) is defined by its thickness $h_{1}$ (resp. $h_{2}$ ), density $\rho_{1}$ (resp. $\rho_{2}$ ) and its average vertical roughness $\sigma_{1}$ (resp. $\sigma_{2}$ ). The bilayer thickness $h_{1}+h_{2}$ defines the periodicity of the stack; the film thickness corresponds to the total stack, i.e. $N \times\left(h_{1}+h_{2}\right)$. The vertical roughness of each layer is related to a distribution of surface heights with positions statistically distributed according to a Gaussian function. ${ }^{21}$ The roughness parameter of each layer $\sigma i$, obtained as the standard deviation of this function, is then introduced in the matrix formalism by multiplication of the matrix coefficients by a Debye-Waller factor $19,22,23$ and also used to describe the density profile of the stack. The average film density was also calculated from the total reflection edge position $\left(\theta_{c}\right)$ using the following equation, the absorption being neglected:

$$
\theta_{c} \sim \sqrt{2 \delta}
$$

with $\delta$ the decrement to 1 of the refractive index, proportional to the electronic or mass density.

\section{RESULTS AND DISCUSSIONS}

The dissolution of four different films was investigated. The main informations are shown on Table 1. No ellipsometry porosimetry experiment was done on film $\mathrm{M}$ thus the pore size is not indicated

Table 1 : Samples characteristics

\begin{tabular}{ccccc}
\hline Samples & $\begin{array}{c}\text { Template with } \\
\text { molar ratio }\end{array}$ & $\begin{array}{c}\text { Thickness } \\
\text { (nm) }\end{array}$ & Porosity & $\begin{array}{c}\text { Pore size } \\
\text { (nm) }\end{array}$ \\
\hline F & F127 $2.5 .10^{-3}$ & 120 & $43 \%$ & 7.7 \\
C & CTAB $5.10^{-2}$ & 230 & $35 \%$ & 3.6 \\
D & F127 $5.10^{-5}$ & 205 & $6 \%$ & microporous \\
M & F127 $2.10^{-3}$ & 310 & $43 \%$ & not probed \\
\hline
\end{tabular}




\section{Dissolution of F127 templated silica films (F) in $50 \mathrm{mM} \mathrm{NH}_{4} \mathrm{~F}$}

The evolution of the refractive index $(n)$ and the relative thickness $(h)$ of film $\mathrm{F}$ with exposition time in the $50 \mathrm{mM} \mathrm{NH}_{4} \mathrm{~F}$ solution is shown on Figure 1. First, up to 270 s of exposition, the refractive index of the film decreases (porosity increase) while the thickness remains constant, suggesting that matter subtraction occurs homogeneously inside the coating throughout the porosity. At 280s of exposition (green), $h$ starts decreasing and $n$ starts increasing, which is expected when a porous structure collapses. This structure modification occurs progressively as the attack carries on. From 450s, both refractive index and thickness simultaneously decrease, up to the full dissolution of the coating.

In order to better assess the structural change and understand the dissolution mechanism, films attacked for 0s, 100s, 280s, and 450s, were further analyzed by ellipsometry porosimetry (Figure 2) and XRR reflectivity (Figure 3 ).

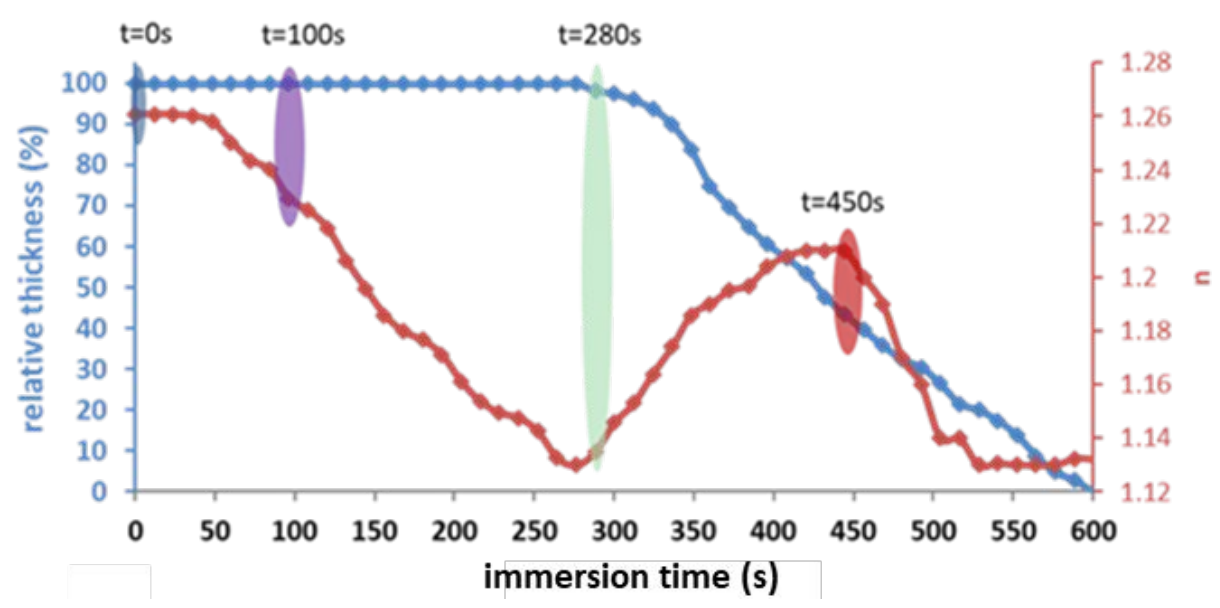

Figure 1 : Evolution of film $F$ with the etching time in $50 \mathrm{mM} \mathrm{NH}_{4} F$ with relative thickness and $n$ obtained by ellipsometry analyses. 
(a)

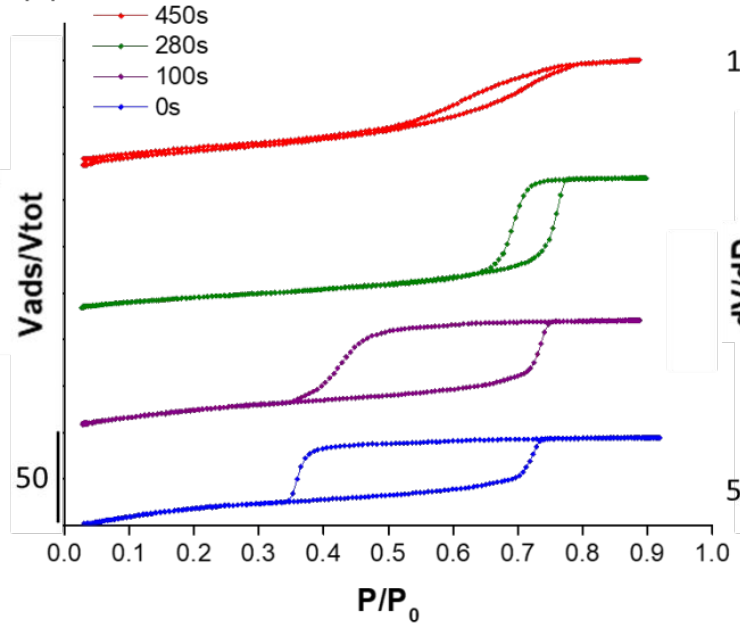

(b)
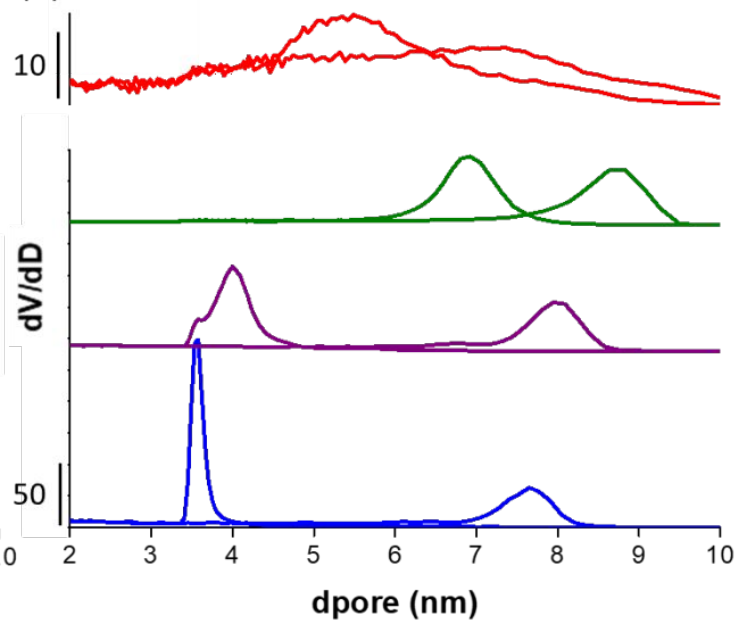

Figure 2: EP analyses of film $F$ with $(a)$ isotherms and $(b)$ corresponding pore and interconnection size distributions

Isotherms and corresponding pore and interconnection size distributions are presented on Figure $2 a$ and $b$, respectively. The isotherm corresponding to film $F$ before etching (blue) displays a large hysteresis due to pore blocking effects and associated with pores of smaller interconnections blocking the desorption (bottleneck pores). With this type of isotherm, only the adsorption branch can be used to estimate the pore size whereas the desorption branch is associated with the interconnections size and not the pore size itself. ${ }^{24}$ It can be observed that the isotherm presents a steep desorption at $p / p_{0}$, close to 0.35 which could correspond to a desorption through cavitation mechanism. If this is the case, the interconnection size distribution could be overestimated. Keeping this in mind, the corresponding pore size distributions indicates an average pore and interconnection size of $7.7 \mathrm{~nm}$ and $3.7 \mathrm{~nm}$, respectively. The pore volume was deduced to be $43 \% \mathrm{vol}$ before dissolution. Looking at the film after 100 s of chemical attack (purple), it can be observed that the overall shape of the isotherm is similar but the porosity increased to $54 \% \mathrm{vol}$; both average pore size and interconnection size have slightly increased to $8.1 \mathrm{~nm}$ and $4 \mathrm{~nm}$, respectively. Since the desorption step is less steep and shifted to $p / p_{0}>0.4$, there is no doubt that the desorption occurs at equilibrium and not by a cavitation mechanism, thus the interconnection size distribution is not overestimated. After 280s of etching (green), the pore volume reached $71 \% \mathrm{vol}$, and the isotherm presents a narrow hysteresis due to the widening of the interconnections. At this point the average pore and interconnection size are $8.8 \mathrm{~nm}$ and $6.9 \mathrm{~nm}$, respectively. After $450 \mathrm{~s}$ (red), the porosity is $54 \% \mathrm{vol}$. The corresponding isotherm is also drastically different with wide adsorption and desorption steps. The average pore and interconnection size are $7 \mathrm{~nm}$ and $5 \mathrm{~nm}$ respectively. This indicates that the porous network has completely collapsed and lost its structural homogeneity as already deduced from the in situ dynamic study shown in Figure 1. 


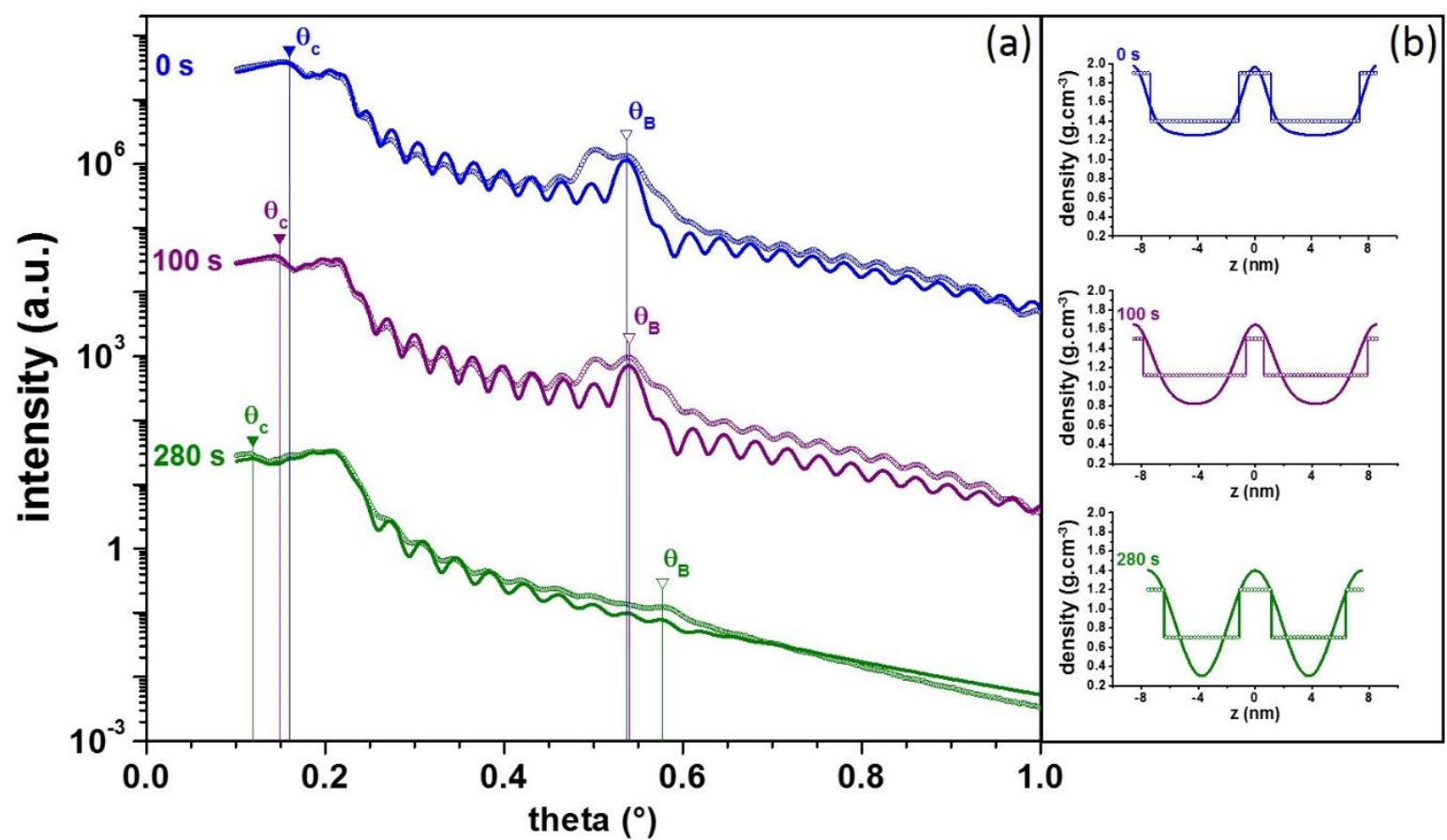

Figure 3 :(a) Experimental and simulated XRR patterns recorded on F127 sample after 0s, 100s and 280s exposition time in the etching solution; the total reflection edge position $\left(\theta_{c}\right)$ and the first Bragg peak $\left(\theta_{B}\right)$ are indicated for each film. (b) Corresponding density profiles obtained from the fit parameters, showing both ideal profiles (no roughness) and profiles including the average roughness deduced from the fits.

Figure 3a and $b$ show the experimental and simulated XRR patterns after 0s, 100s and 280s exposition time in etching solution (the diagram corresponding to 450 s exhibits no features and is thus not plotted in this figure but is given in $\mathrm{SI}$ ), with the corresponding density profiles deduced from the simulation parameters. First, for each sample, two critical angles are observed: the first one (labelled $\theta_{\mathrm{c}}$ ) corresponds to the average density of the film, and the second (not labelled) to the one on the Si substrate. Secondly, the XRR patterns exhibit well-defined Kiessig fringes indicating uniform films up to 280 s exposition time. Then, the appearance of diffraction peaks recorded at the Bragg position $\theta_{B}$ reveals that the coatings are ordered, corresponding to an out-of-plane periodicity of $8.46 \mathrm{~nm}$ and $8.36 \mathrm{~nm}$ after respectively $0 \mathrm{~s}$ and $100 \mathrm{~s}$ exposition time, in agreement with the pore size. A lower periodicity of $7.15 \mathrm{~nm}$ is observed at $280 \mathrm{~s}$, most likely due to the beginning of the collapsing process. Additional XRR plots, in linear scale and corrected from the $Q^{4}$ reflectivity decrease, are provided in SI to better assess the position of the Bragg peaks. Besides, XRR analyses are further consistent with the EP analysis: the density profiles clearly shows (i) the pore enlargement with almost a constant periodicity (same $\theta_{B}$ as for Os) and a constant film thickness (Kiessig fringes at the same position) with a decrease in the average film density (smaller $\theta_{c}$ ) after 100s exposition time; and (ii) the decrease of the periodic distance (shift of $\theta_{B}$ through higher angle) and film thickness (larger Kiessig fringes) as and the 
low value of film density (smaller $\theta_{c}$ ) after 280 s exposition time. After 450 s exposition time, the pore periodicity is probably too low and the surface roughness too high to enable any Bragg peak or Kiessig fringe to be detectable by XRR (see SI). Table 2 summarizes coatings characteristics deduced from both techniques.

Table 2 : Summary of the evolution of film F density and thickness with immersion time within the $50 \mathrm{mM} \mathrm{NH}_{4} \mathrm{~F}$ obtained by XRR and EP analyses.

\begin{tabular}{|c|c|c|c|c|c|c|}
\hline \multirow[b]{2}{*}{$\begin{array}{l}\text { Exposition } \\
\text { time }\end{array}$} & \multicolumn{3}{|c|}{ XRR } & \multicolumn{3}{|c|}{ Ellipsometry } \\
\hline & $\begin{array}{l}\text { Density from } \theta \mathrm{c} \\
\text { position }\left(\mathrm{g} . \mathrm{cm}^{-3}\right)\end{array}$ & $\begin{array}{l}\text { Density from } \\
\text { fit }\left(\mathrm{g} \cdot \mathrm{cm}^{-3}\right)\end{array}$ & $\begin{array}{c}\mathrm{h} \\
(\mathrm{nm})\end{array}$ & $\begin{array}{l}\text { Density } \\
\left(\mathrm{g} . \mathrm{cm}^{-3}\right)\end{array}$ & $\begin{array}{c}\mathrm{h} \\
(\mathrm{nm})\end{array}$ & $\mathbf{n}$ \\
\hline Os & 1.42 & 1.45 & 121 & 1.48 & 120 & 1.26 \\
\hline $100 \mathrm{~s}$ & 1.21 & 1.14 & 120 & 1.20 & 120 & 1.23 \\
\hline $280 s$ & 0.79 & 0.85 & 109 & 0.75 & 119 & 1.13 \\
\hline $450 s$ & 1.22 & - & - & 1.20 & 54 & 1.21 \\
\hline
\end{tabular}

As a result, we can conclude that the applied treatment up to 280 s allows to increase the porosity from $43 \%$ to $71 \%$ through enlargement of the pores, and also of the interconnections in a greater extend, which leads to a significant increase of the porous network accessibility. Interestingly, the persistence of the Bragg diffraction peak, together with the stability of the thickness and the narrow distribution of the pore size, confirm that the inner mesostructure has not been significantly modified. The enlargement of the interconnections is more important than that of the pores. This is expected, as in such low $\mathrm{F}^{-}$concentration a local dissolution and recondensation of the silica moieties occurs by Oswald ripening mechanism which leads to reorganization of the porous network with sharp, high curvature features being eliminated first. Assuming that the etching efficiency is homogeneous throughout the film, small interconnections first undergo an Oswald ripening, leading to a significant increase of the interconnection size but only a slight increase of the pore dimension. Upon further dissolution ( $t>280 \mathrm{~s}$ ) the film starts to collapse, as confirmed by a decrease of thickness, the decrease of the average pore size, the loss of the pore periodicity and the widening of the pore and interconnection size distributions.

\section{Dissolution of CTAB templated silica films (C) in $50 \mathrm{mM} \mathrm{NH}_{4} \mathrm{~F}$}

To verify if the dissolution process observed for the previous film $\mathrm{F}$ can be generalized to films with different characteristics (pore dimension, thickness, porosity, meso-structuration), the same ellipsometry investigations were performed on a CTAB templated film (C) and results are displayed in Figure 4 and 5 . The evolutions of the film thickness and refractive index with the etching time are similar to that measured on film $\mathrm{F}$. One can thus make the same interpretation except that the film starts to collapse after 720s, which is much longer. Additionally, the immersion time needed for complete dissolution (1600s) is higher than the one of film F. This is 
due to three main differences that are the presence of smaller pores, a lower porosity (i.e. $35 \%$ vs $43 \%$ ), and a greater thickness (i.e. $230 \mathrm{~nm}$ vs $120 \mathrm{~nm}$ ). First, the thickness difference implies a greater amount of material to dissolve for the $C$ film. In addition, on one hand, smaller pore size is accompanied by greater specific surface area which should increase the speed of dissolution. On the other hand, the diffusion of reactants and products inside and outside the coating, respectively, must be lower for smaller pores, which seems to dominate here.

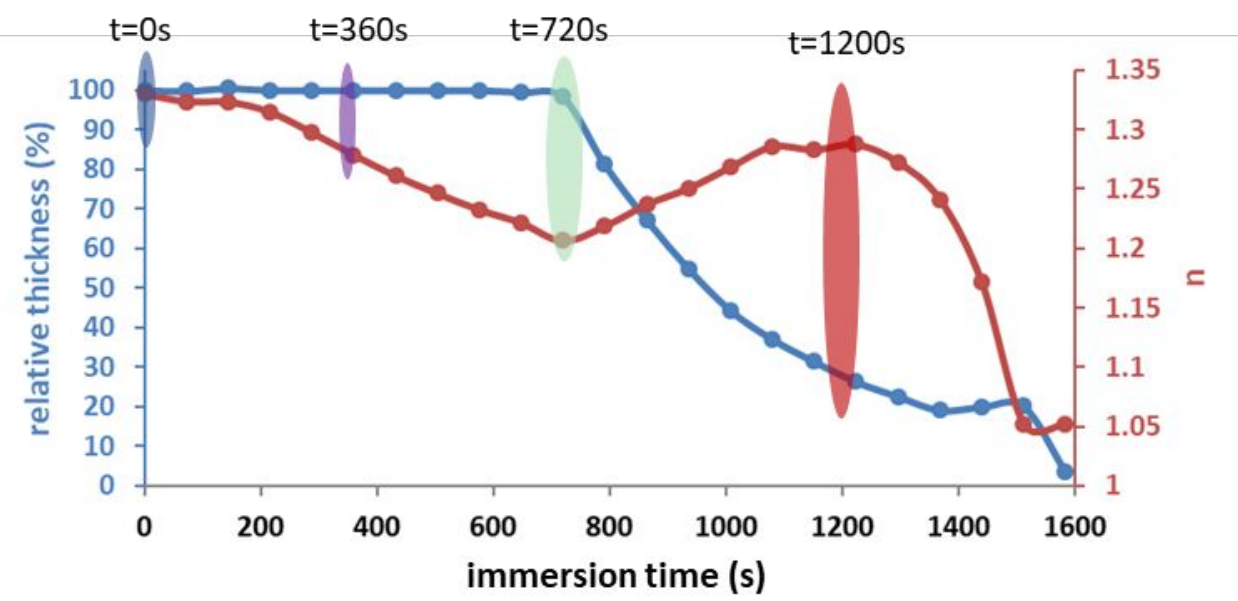

Figure 4 : Evolution of film relative thickness and $n$ with etching time in 50mM NH4F. The colored ellipses correspond to the zones analyzed by EP in Figure 5

(a)

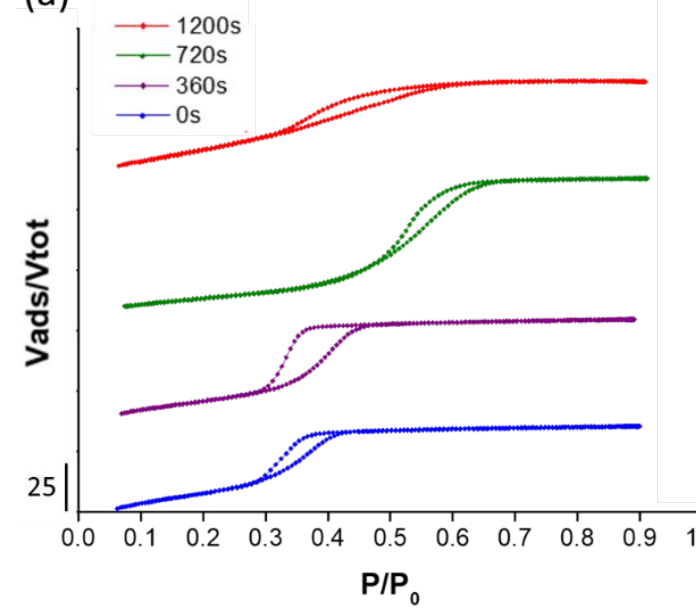

(b)

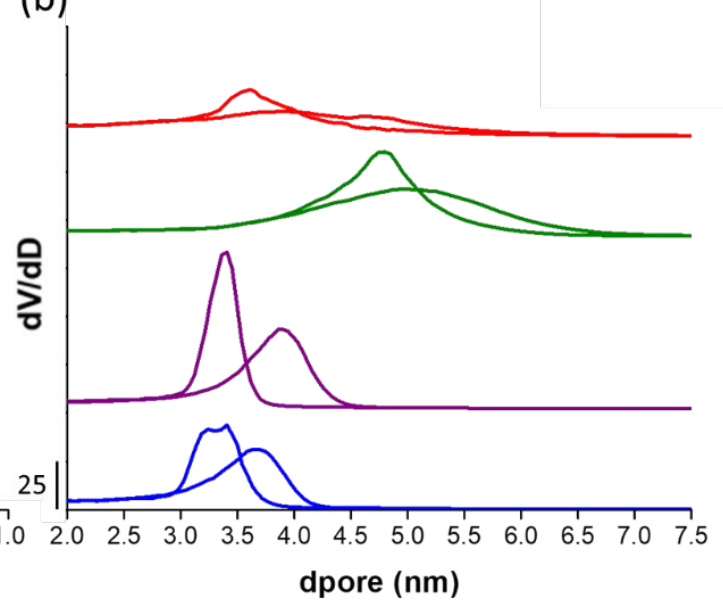

Figure 5 : EP analyses of film C with (a) isotherms (b) corresponding pore and interconnection size distributions

Corresponding isotherms are provided in Figure 5. Before etching, the isotherm (blue) displays a narrow hysteresis. In this scenario, it cannot be concluded if there are slight pore blocking effects or if the hysteresis is only due to the adsorption occurring under sursaturation conditions. We thus assumed that slight pore blocking effects are present. Even if this assumption is wrong, this 
is not critical to study the evolution of the dissolution. Keeping this in mind, the average pore and interconnection size are $3.6 \mathrm{~nm}$ and $3.3 \mathrm{~nm}$, respectively. After 360s of chemical attack (purple curve), both average pore size and interconnection size have slightly increased to $3.9 \mathrm{~nm}$ and 3.4 $\mathrm{nm}$, respectively. In the same way as for film $\mathrm{F}$, they remain narrow. After 720 s of etching (green), the average pore and interconnection size are $5.0 \mathrm{~nm}$ and $4.7 \mathrm{~nm}$, respectively. The pore and interconnection size distributions have already started to widen, which could be due to the collapse of the thinnest pore walls, thus forming galleries of different sizes. This may be due to the fact that pore and interconnection dimensions are very close. Furthermore, at this point the film is on the verge of collapsing, as indicated by the imminent decrease of thickness. After $1200 \mathrm{~s}$ (red), the film has collapsed and the pore and interconnection size distributions are very wide, with average pore and interconnection size of $4.3 \mathrm{~nm}$ and $3.6 \mathrm{~nm}$, respectively. Overall, with the $\mathrm{NH}_{4} \mathrm{~F}$ etching, it was possible to tune the porosity of the film C from $35 \%$ to $56 \%$ effectively increasing the average pore size from $3.6 \mathrm{~nm}$ to $5 \mathrm{~nm}$ and the interconnection size from $3.4 \mathrm{~nm}$ to $4.7 \mathrm{~nm}$. In a similar way than what was observed for film F, making the film porosity more accessible through controlled dissolution is clearly possible. One may conclude that the observed behavior is general for all mesoporous silica coatings prepared with the same sol-gel conditions.

\section{Kinetics of dissolutions}

Time-resolved ellipsometry investigation data can be exploited to plot the quantity (volume) of dissolved materials versus immersion time (detailed calculations provided in the experimental section). These are provided in Figure $6 a, b$ and $c$ for both mesoporous films $F$ and $C$, as well as for the dense film $D$ elaborated without templating agent.
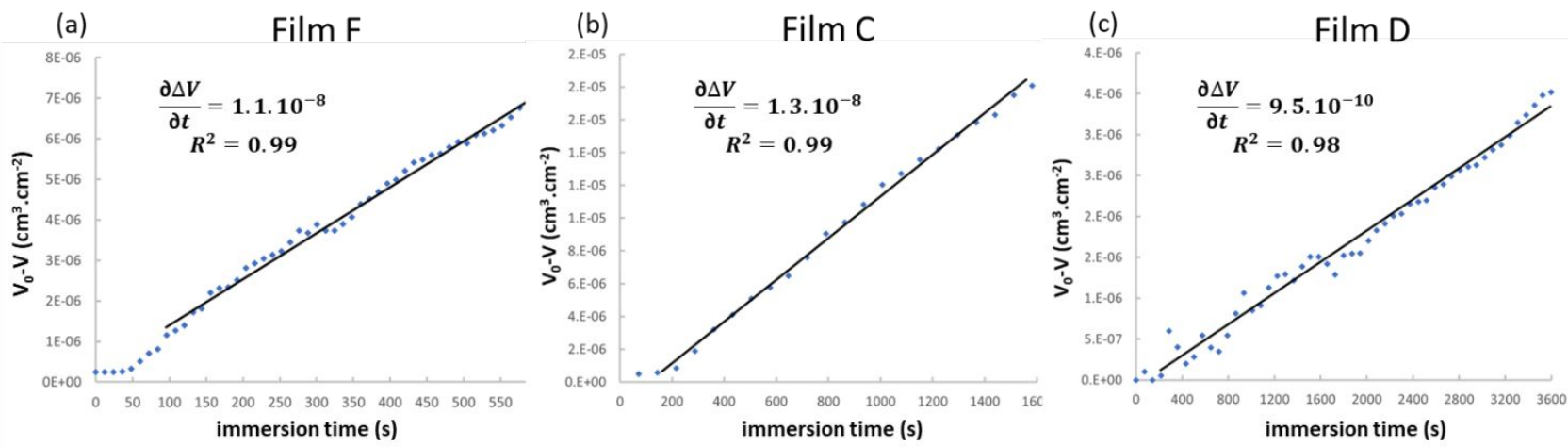

Figure 6: Volume of dissolved material versus time and corresponding etching rates of (a) film $F(b)$ film C and (c) film D

For film $\mathrm{F}$, in the beginning of the chemical attack from 0 to 50 s negligible etching is observed. This could be due to the slow initial diffusion of fluoride species to the surface of the coating. Then, after 50s of chemical attack, a linear tendency is observed with a constant etching rate of $1.1 .10^{-8} \mathrm{~cm}^{3} \cdot \mathrm{cm}^{-2} \cdot \mathrm{s}^{-1}$. The etching plot of film $\mathrm{C}$ presents a similar behavior, with an etching rate of $1.3 .10^{-8} \mathrm{~cm}^{3} \cdot \mathrm{cm}^{-2} \cdot \mathrm{s}^{-1}$, close to the etching rate of sample $\mathrm{F}$, even though the films have different 
specific surface area and pore size. The fact that these rates are close and constant along the dissolution process, up to film destruction, even though there is a modification of the film structure (demonstrated by the previous parts) shows that dissolution is not significantly affected by the structural changes such as the mesopore average size.

However, the dense coating (film D) exhibits a constant etching rate of $9 \cdot 5 \cdot 10^{-10} \mathrm{~cm}^{3} \cdot \mathrm{cm}^{-2} \cdot \mathrm{s}^{-1}$, one order of magnitude lower than the mesoporous coatings. Despite a porosity of $6 \%$, the dense film (D) bears exclusively an intrinsic microporosity that is far more difficult to penetrate by the fluoride reactant if compared to the mesoporous films. Additionally, in this case, the specific surface area is considerably lower than for film F and C, and could also limit the reaction speed due to a much smaller number of reaction sites.

Finally, one must verify that the concentration of fluoride species does not change into the solution volume all along the dissolution period, as this would influence the etching rate. This is verified as followed:

The number of moles of $\mathrm{Si}$ atoms in the coating $\mathrm{nmol}_{S i}$ can be obtained using the following equation, where $h, S, P$ are the coating thickness, the deposited surface and the porosity, respectively. $d_{\mathrm{SiO}_{2}}$ is the amorphous silica density $\left(2.2 \mathrm{~g} \cdot \mathrm{cm}^{-3}\right)$ and $M_{\mathrm{SiO}_{2}}$ is the silica molar weight $\left(60.08 \mathrm{~g} \cdot \mathrm{mol}^{-1}\right)$.

$$
\operatorname{nmol}_{\mathrm{Si}}=\operatorname{nmol}_{\mathrm{SiO}_{2}}=\frac{V_{f_{i l m}(1-P) d_{\mathrm{SiO}_{2}}}}{M}=\frac{h S(1-P) d_{\mathrm{SiO}_{2}}}{M}
$$

For coating $\mathrm{F}: h=120 \mathrm{~nm}, S=7.5 \mathrm{~cm}^{2}$ and $\mathrm{P}=43 \%$, consequently $1.88 .10^{-6} \mathrm{~mol}$ of $\mathrm{Si}^{4+}$ compose the coating. The dissolution was done using $250 \mathrm{ml}$ of a $50 \mathrm{mM} \mathrm{NH}_{4} \mathrm{~F}$ solution which corresponds to $1.25 .10^{-2} \mathrm{~mol}$ of $\mathrm{F}^{-}$ions. The amount of $\mathrm{Si}^{4+}$ that can be etched from the coating is 4 orders of magnitude lower than the amount of fluoride present in the solution. Even if $6 \mathrm{~F}^{-}$ions are needed per etched $\mathrm{Si}^{4+}$, the decreasing of fluoride concentration in the solution is too low to affect the rate of dissolution. This is also true for films $C$ and $D$.

One may thus conclude that for high specific surface area materials such as mesoporous silica thin films $(P>30 \%)$, the etching rate is limited by the diffusion of fluoride species. This is not necessarily the case when the specific surface area is significantly decreased such as for films elaborated without templating agent.

To get a better understanding of the etching, the mechanism of attack of fluoride ions on the silica network must be considered. Etching of $\mathrm{SiO}_{2}$ in $\mathrm{HF}$-based solutions is highly dependent on the $\mathrm{pH}$. In our case, $\mathrm{NH}_{4} \mathrm{~F}$ dissociates into weak acid $\mathrm{NH}_{4}{ }^{+}$and its counter ions $\mathrm{F}^{-}$. At $50 \mathrm{mM}$ the $\mathrm{pH}$ of the solution is close to 6 . The etching mechanism of a plane silica surface in this range of $\mathrm{pH}$ was investigated and discussed by Knotter and coworkers. ${ }^{25}$ For a mesoporous film, fours steps involving diffusion and chemical attack can be distinguished (Figure 7). 


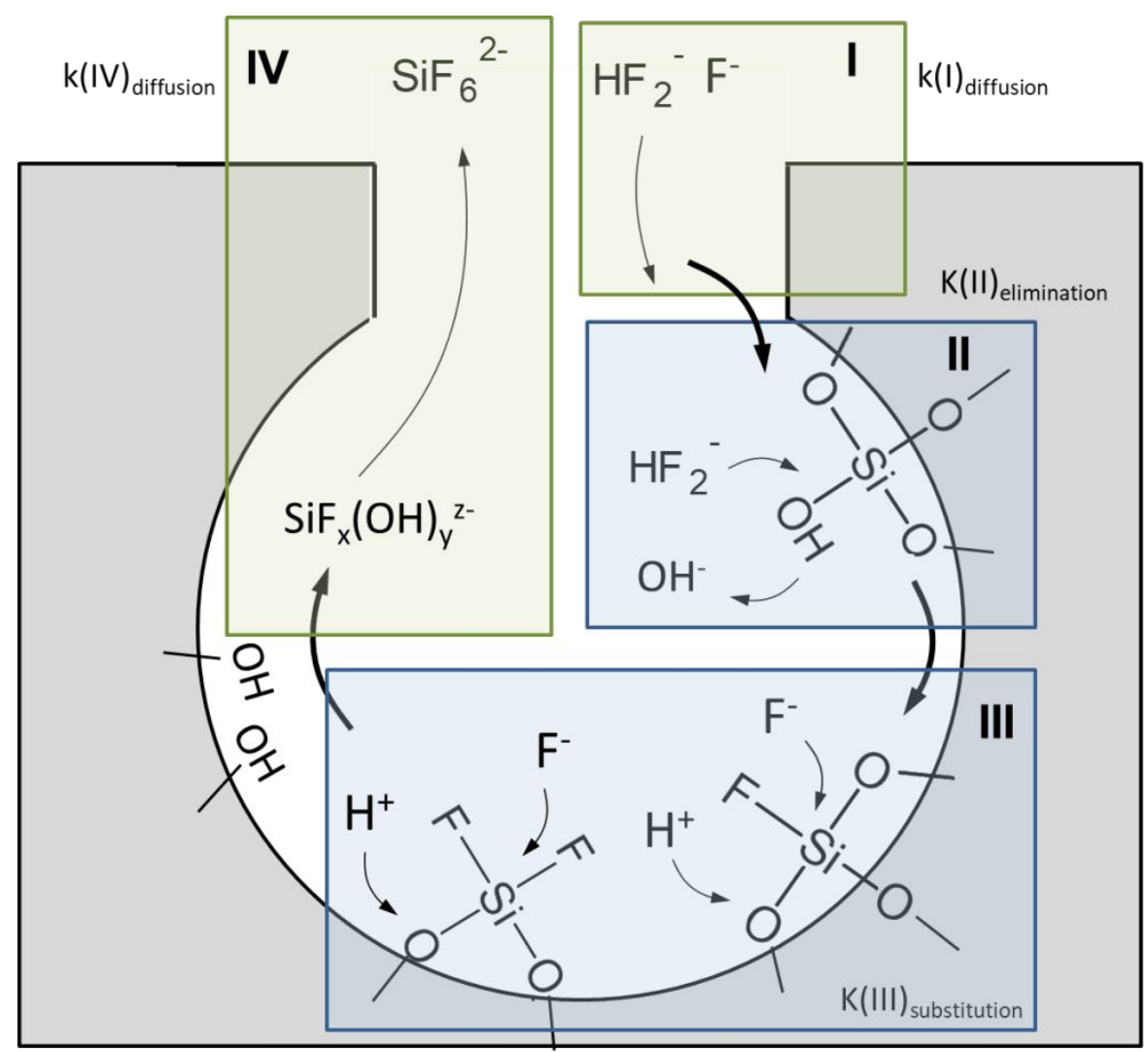

Figure 7 : Mechanism of dissolution of $\mathrm{SiO}_{2}$ with diffusion steps (green) and reaction steps (blue)

The first step corresponds to the diffusion of fluoride from the solution towards the surface of the film and inside the porosity. The second step is the attack of Si center by fluoride reactants accompanied by the release of $\mathrm{OH}^{-}$. Knotter and coworkers ${ }^{25}$ proposed that $\mathrm{OH}^{-}$departure is triggered by $\mathrm{HF}^{2-}$ attack, followed by fluorination. Additionally, at $\mathrm{pH}=6$ the silica surface is negatively charged which also facilitates the elimination of $\mathrm{OH}^{-}$. In the third step, the following fluorinations occur by multiple consecutive nucleophilic substitutions with $\mathrm{F}^{-}$until separation from the bulk $\mathrm{SiO}_{2}$ matrix of $\mathrm{SiF}_{x}(\mathrm{OH})_{y}{ }^{2}$ ions. The nucleophilic substitution (step III) being 20 times faster ${ }^{25}$ than the $\mathrm{OH}^{-}$elimination (step II), it is never a limiting step even though it occurs multiple times. It can also be noted that in Figure 7, only one silanol group is represented on the surface. However, in sol-gel silica films two $\mathrm{OH}$ groups may be present on the Si center of the surface, and in such a configuration, a faster reaction is expected because two leaving groups are present. Finally, in the last step (IV) the $\mathrm{SiF}_{\mathrm{x}}(\mathrm{OH})_{\mathrm{y}}{ }^{2-}$ ions are eventually converted to $\mathrm{SiF}_{6}{ }^{2-}$ ions which diffuse from the pore surface to the edge of the porosity and to the solution. Step II and III are chemical reaction steps that dependent on both the fluoride ions concentration and the number of reaction sites available, which are directly linked to the specific surface area of the coating. Step I and IV are diffusion steps, also dependent on the fluoride ions concentration but not on the specific surface of the coating. However, the diffusion is affected by the pore network accessibility and the wall surface charge (sign and density). Indeed, the presence of pore necks should hinder the diffusion of fluoride species if they are too small. Additionally, due to the 
negative surface charge of silica at $\mathrm{pH}=6$, an electrostatic repulsion between the pore surface and the anionic fluoride species exists, also hindering the diffusion inside the porosity.

Going back to the etching rates, if we assume that the porosity of the dense film (D) cannot be infiltrated by the fluoride species, the etching sites lay on the surface of the film and their density is thus restricted to this same surface. As a result, if enough reactant is present in the solution with respect to the density of etching site, the rate is likely to be limited by the chemical attack in step II. In presence of a mesoporosity, infiltration of the fluoride species inside the material is possible and the density in available etching sites dramatically increases, which leads to a faster rate, as it is observed. However, the rate is not proportional to the surface area since one must account for the diffusion of the reactant inside the material that depends on the accessibility. In addition, the ratio of reactant molecules on the number of available sites is lower than for the dense film. We do observe that the rate is faster for mesoporous films ( $F$ and $C$ ), but they are almost equivalent, while they have different pore size distribution and specific surface area. In this case the reaction must be limited by the diffusion of species (step I and IV).

\section{Influence of $\mathrm{NH}_{4} \mathrm{~F}$ concentration}

Etching plots for coatings $\mathrm{F}$ immersed in $\mathrm{NH}_{4} \mathrm{~F}$ solutions of lower $(5 \mathrm{mM})$ and higher $(200 \mathrm{mM})$ concentrations are provided in Figure $8 a$ and $b$, respectively.

(a)

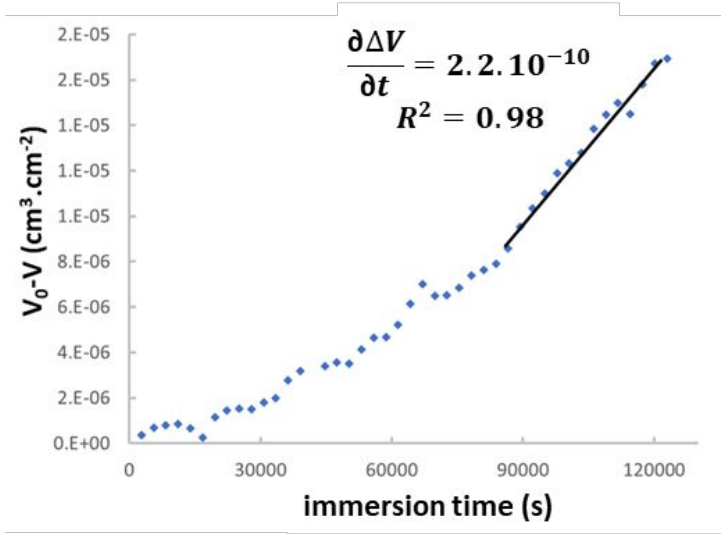

(b)

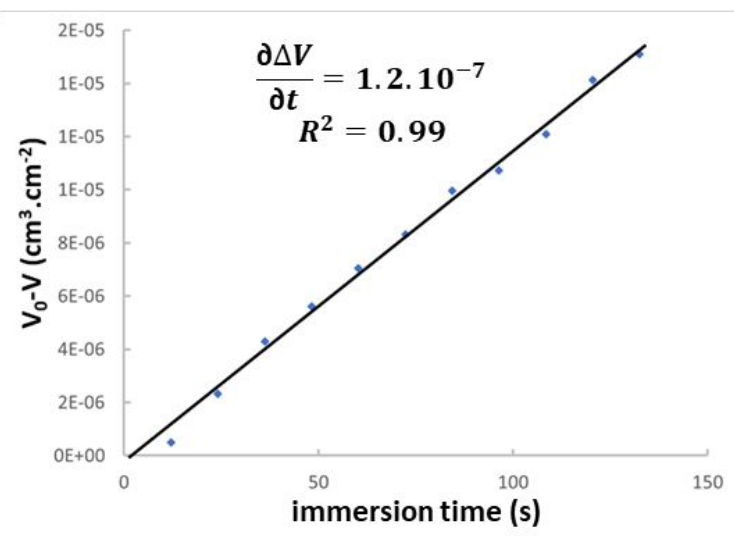

Figure 8 : Volume of dissolved material versus time and corresponding etching rates of film $\mathrm{F}$ in a (a) $5 \mathrm{mM}$ and (b) $200 \mathrm{mM}$ NH4F solution

In the $5 \mathrm{mM}$ solution, the etching rate is much slower than in the $50 \mathrm{mM}$ one: it increases slowly until $90000 \mathrm{~s}$ and stabilizes at a constant etching rate of $2 \cdot 2 \cdot 10^{-10} \mathrm{~cm}^{3} \cdot \mathrm{cm}^{-2} \cdot \mathrm{s}^{-1}$, which is 50 time slower than in $50 \mathrm{mM}$. In $200 \mathrm{mM}$, a constant etching rate of $1.2 \cdot 10^{-7} \mathrm{~cm}^{3} \cdot \mathrm{cm}^{-2} \cdot \mathrm{s}^{-1}, 10$ times faster than in $50 \mathrm{mM}$, is readily observed. As already mentioned, the etching rate is highly dependent on the reactant concentration, which impacts all steps of the dissolution mechanism. Interestingly, at low $\mathrm{NH}_{4} \mathrm{~F}$ concentrations, more than 20 hours are needed to achieve a constant 
rate, which is likely due to the longer time needed by the reactant to infiltrate the porosity and achieve a local critical concentration.

In the aim of selecting the most practical solution concentration for pore size tuning, Table 3 summarizes the etching speeds that were obtained for film $\mathrm{F}$ with different $\mathrm{NH}_{4} \mathrm{~F}$ concentrations. Although the $200 \mathrm{mM}$ solution allowed to increase the etching rate tenfold, the film was completely dissolved in 130s, which makes it more difficult to precisely control the dissolution. In the contrary, the $5 \mathrm{mM}$ solution led to a very slow etching with a varying rate, making it much more time-consuming to use. In the end, a $50 \mathrm{mM} \mathrm{NH}_{4} \mathrm{~F}$ gives a good compromise between control of the dissolution and faster etching rate to tune the porosity of mesoporous silica coatings.

Table 3 : Etching rate and time needed for destruction of film $\mathrm{F}$ with different $\mathrm{NH}_{4} \mathrm{~F}$ concentration.

\begin{tabular}{|c|ccc|}
\cline { 2 - 4 } \multicolumn{1}{c|}{} & $\mathrm{NH}_{4} \mathrm{~F} 5 \mathrm{mM}$ & $\mathrm{NH}_{4} \mathrm{~F} 50 \mathrm{mM}$ & $\mathrm{NH}_{4} \mathrm{~F} 200 \mathrm{mM}$ \\
\hline $\begin{array}{c}\text { Etching rate }\left(\mathrm{cm}^{3} \cdot \mathrm{cm}^{-2} \cdot \mathrm{s}^{-1}\right) \\
\text { Etching time for film } \\
\text { complete destruction }\end{array}$ & $2.2 .10^{-10}$ & $1.12 .10^{-8}$ & $1.18 .10^{-7}$ \\
& $36 \mathrm{~h}$ & $10 \mathrm{~min}$ & $130 \mathrm{~s}$ \\
\hline
\end{tabular}

\section{Etching of hydrophobic film $\mathrm{M}$ in $\mathrm{NH}_{4} \mathrm{~F}$}

Finally, the etching treatment was applied to a mesoporous hydrophobic film (film M) composed of methylated hydrophobic silica (see experimental). Upon exposition to a $50 \mathrm{mM} \mathrm{NH}_{4} \mathrm{~F}$ solution, the film showed no evolution of porosity and thickness until its complete delamination from the substrate. The same behavior was observed using the $200 \mathrm{mM} \mathrm{NH}_{4} \mathrm{~F}$ solution. This means that the film itself was not attacked by the solution and the delamination was caused by the dissolution of the natural dense $\mathrm{SiO}_{2}$ layer between the sol-gel film and the Si substrate. The fact that the hydrophobic film is not attacked is in accordance with the etching mechanism proposed in Figure 7, as in step II surface $\mathrm{OH}$ groups are replaced by $\mathrm{CH}_{3}$ groups which cannot be attacked in the solution, preventing the fluorination. This opens a path for potential selective etching if a film is elaborated with hydrophobic and hydrophilic parts. This could be used for patterning thin films using $\mathrm{NH}_{4} \mathrm{~F}$ etching.

\section{CONCLUSION}

In this work, mesoporous silica thin films were elaborated through the sol-gel method using different templating agents. The films were then exposed to a $\mathrm{NH}_{4} \mathrm{~F}$ solution to induce dissolution. It was shown by EP in combination with XRR measurements that the pore and 
interconnection size could be tuned while keeping the pore organization of the film. Pore interconnections showed a faster enlargement than the pores, which is an efficient strategy to increase their accessibility. The etching rates of different films were investigated, and the mechanism of dissolution, consisting in two diffusion steps and two chemical reaction steps was discussed. It was shown that the etching process is limited by the accessible surface area of the film only if this surface is low enough, such as for a dense coating. When the surface is high enough such as for a mesoporous film, it was proposed that the diffusion of the species becomes the limiting factor of the etching process. The study of different concentrations allowed to give the most practical range of concentration for the controlled dissolution of mesoporous silica films. Finally, it was shown that hydrophobic silica films were not attacked by the $\mathrm{NH}_{4} \mathrm{~F}$ solution, which could be exploited to do selective etching of a coating.

\section{ASSOCIATED CONTENT}

\section{Supporting Information}

Detailed representation of the idealized stack model used to extract pore dimension, film thickness and average density profile from XRR analysis. Additional XRR data showing the absence of diffraction peak for coating $F$ after 450 s of dissolution.

\section{ACKNOWLEDGEMENTS}

We acknowledge DSM for their financial support, as well as acknowledge the AQUARIUS project, which has received funding from the European Union's Horizon 2020 research and innovation program under grant agreement No. 731465. 


\section{REFERENCES}

(1) Alberti, S.; Soler-Illia, G. J. A. A.; Azzaroni, O. Gated Supramolecular Chemistry in Hybrid Mesoporous Silica Nanoarchitectures: Controlled Delivery and Molecular Transport in Response to Chemical, Physical and Biological Stimuli. Chem. Commun. 2015, 51 (28), 6050-6075. https://doi.org/10.1039/C4CC10414E.

(2) Lepoutre, S.; Smått, J.-H.; Laberty, C.; Amenitsch, H.; Grosso, D.; Lindén, M. Detailed Study of the Pore-Filling Processes during Nanocasting of Mesoporous Films Using SnO2/SiO2 as a Model System. Microporous Mesoporous Mater. 2009, 123 (1-3), 185-192. https://doi.org/10.1016/j.micromeso.2009.03.047.

(3) Lepoutre, S.; Julián-López, B.; Sanchez, C.; Amenitsch, H.; Linden, M.; Grosso, D. Nanocasted Mesoporous Nanocrystalline ZnO Thin Films. J Mater Chem 2010, 20 (3), 537542. https://doi.org/10.1039/B912613A.

(4) Pérez, M. D.; Otal, E.; Bilmes, S. A.; Soler-Illia, G. J. A. A.; Crepaldi, E. L.; Grosso, D.; Sanchez, C. Growth of Gold Nanoparticle Arrays in $\mathrm{TiO}_{2}$ Mesoporous Matrixes. Langmuir 2004, 20 (16), 6879-6886. https://doi.org/10.1021/la0497898.

(5) Mercuri, M.; Pierpauli, K.; Bellino, M. G.; Berli, C. L. A. Complex Filling Dynamics in Mesoporous Thin Films. Langmuir 2017, 33 (1), 152-157. https://doi.org/10.1021/acs.langmuir.6b03987.

(6) Ceratti, D. R.; Faustini, M.; Sinturel, C.; Vayer, M.; Dahirel, V.; Jardat, M.; Grosso, D. Critical Effect of Pore Characteristics on Capillary Infiltration in Mesoporous Films. Nanoscale 2015, 7 (12), 5371-5382. https://doi.org/10.1039/C4NR03021D.

(7) Ravichandran, R.; Sundaramurthi, D.; Gandhi, S.; Sethuraman, S.; Krishnan, U. M. Bioinspired Hybrid Mesoporous Silica-Gelatin Sandwich Construct for Bone Tissue Engineering. Microporous Mesoporous Mater. 2014, 187, 53-62. https://doi.org/10.1016/j.micromeso.2013.12.018.

(8) Nishijima, Y.; Ueno, K.; Juodkazis, S.; Mizeikis, V.; Misawa, H.; Tanimura, T.; Maeda, K. Inverse Silica Opal Photonic Crystals for Optical Sensing Applications. Opt. Express 2007, 15 (20), 12979. https://doi.org/10.1364/OE.15.012979.

(9) Kaune, G.; Haese-Seiller, M.; Kampmann, R.; Moulin, J.-F.; Zhong, Q.; Müller-Buschbaum, P. TOF-GISANS Investigation of Polymer Infiltration in Mesoporous TiO2 Films for Photovoltaic Applications. J. Polym. Sci. Part B Polym. Phys. 2010, 48 (14), 1628-1635. https://doi.org/10.1002/polb.21964.

(10) El Mourabit, S.; Guillot, M.; Toquer, G.; Cambedouzou, J.; Goettmann, F.; Grandjean, A. Stability of Mesoporous Silica under Acidic Conditions. RSC Adv. 2012, 2 (29), 10916. https://doi.org/10.1039/c2ra21569a.

(11) Bardeau, J.-F.; Gourbil, A.; Dutreilh-Colas, M.; Dourdain, S.; Mehdi, A.; Gibaud, A. X-Ray Reflectivity Study of Acid-Base Post-Synthesis Treatments of Mesoporous Thin Films Templated by P123. Thin Solid Films 2006, 495 (1-2), 191-196. https://doi.org/10.1016/j.tsf.2005.08.357. 
(12) Kobayashi, M.; Susuki, K.; Otani, T.; Enomoto, S.; Otsuji, H.; Kuroda, Y.; Wada, H.; Shimojima, A.; Homma, T.; Kuroda, K. Thickness Control of 3-Dimensional Mesoporous Silica Ultrathin Films by Wet-Etching. Nanoscale 2017, 9 (24), 8321-8329. https://doi.org/10.1039/C7NR01560G.

(13) Osseo-Asare, K. Etching Kinetics of Silicon Dioxide in Aqueous Fluoride Solutions: A Surface Complexation Model. J. Electrochem. Soc. 1996, 143 (4), 1339. https://doi.org/10.1149/1.1836640.

(14) Minhao, Y.; Henderson, M. J.; Gibaud, A. On the Etching of Silica and Mesoporous Silica Films Determined by X-Ray Reflectivity and Atomic Force Microscopy. Thin Solid Films 2009, 517 (9), 3028-3035. https://doi.org/10.1016/j.tsf.2008.12.017.

(15) Grosso, D.; Cagnol, F.; Soler-Illia, G. J. de A. A.; Crepaldi, E. L.; Amenitsch, H.; BrunetBruneau, A.; Bourgeois, A.; Sanchez, C. Fundamentals of Mesostructuring Through Evaporation-Induced Self-Assembly. Adv. Funct. Mater. 2004, 14 (4), 309-322. https://doi.org/10.1002/adfm.200305036.

(16) Boissiere, C.; Grosso, D.; Lepoutre, S.; Nicole, L.; Bruneau, A. B.; Sanchez, C. Porosity and Mechanical Properties of Mesoporous Thin Films Assessed by Environmental Ellipsometric Porosimetry. Langmuir 2005, 21 (26), 12362-12371. https://doi.org/10.1021/la050981z.

(17) Verdaguer, A.; Weis, C.; Oncins, G.; Ketteler, G.; Bluhm, H.; Salmeron, M. Growth and Structure of Water on $\mathrm{SiO}_{2}$ Films on Si Investigated by Kelvin Probe Microscopy and in Situ X-Ray Spectroscopies. Langmuir 2007, 23 (19), 9699-9703. https://doi.org/10.1021/la700893w.

(18) Asay, D. B.; Kim, S. H. Evolution of the Adsorbed Water Layer Structure on Silicon Oxide at Room Temperature. J. Phys. Chem. B 2005, 109 (35), 16760-16763. https://doi.org/10.1021/jp053042o.

(19) X-Ray and Neutron Reflectivity: Principles and Applications; Daillant, J., Gibaud, A., Eds.; Lecture notes in physics; Springer: Berlin, 1999.

(20) Dourdain, S.; Bardeau, J.-F.; Colas, M.; Smarsly, B.; Mehdi, A.; Ocko, B. M.; Gibaud, A. Determination by X-Ray Reflectivity and Small Angle $\mathrm{x}$-Ray Scattering of the Porous Properties of Mesoporous Silica Thin Films. Appl. Phys. Lett. 2005, 86 (11), 113108. https://doi.org/10.1063/1.1887821.

(21) Stearns, D. G. The Scattering of $x$ Rays from Nonideal Multilayer Structures. J. Appl. Phys. 1989, 65 (2), 491-506. https://doi.org/10.1063/1.343131.

(22) Névot, L.; Croce, P. Caractérisation Des Surfaces Par Réflexion Rasante de Rayons X. Application à l'étude Du Polissage de Quelques Verres Silicates. Rev. Phys. Appliquée 1980, 15 (3), 761-779. https://doi.org/10.1051/rphysap:01980001503076100.

(23) Névot, L.; Pardo, B.; Corno, J. Characterization of X-UV Multilayers by Grazing Incidence XRay Reflectometry. Rev. Phys. Appliquée 1988, 23 (10), 1675-1686. https://doi.org/10.1051/rphysap:0198800230100167500.

(24) Thommes, M.; Cychosz, K. A. Physical Adsorption Characterization of Nanoporous Materials: Progress and Challenges. Adsorption 2014, 20 (2-3), 233-250. https://doi.org/10.1007/s10450-014-9606-z.

(25) Knotter, D. M. Etching Mechanism of Vitreous Silicon Dioxide in HF-Based Solutions. J. Am. Chem. Soc. 2000, 122 (18), 4345-4351. https://doi.org/10.1021/ja993803z. 


\section{TOC graphic}

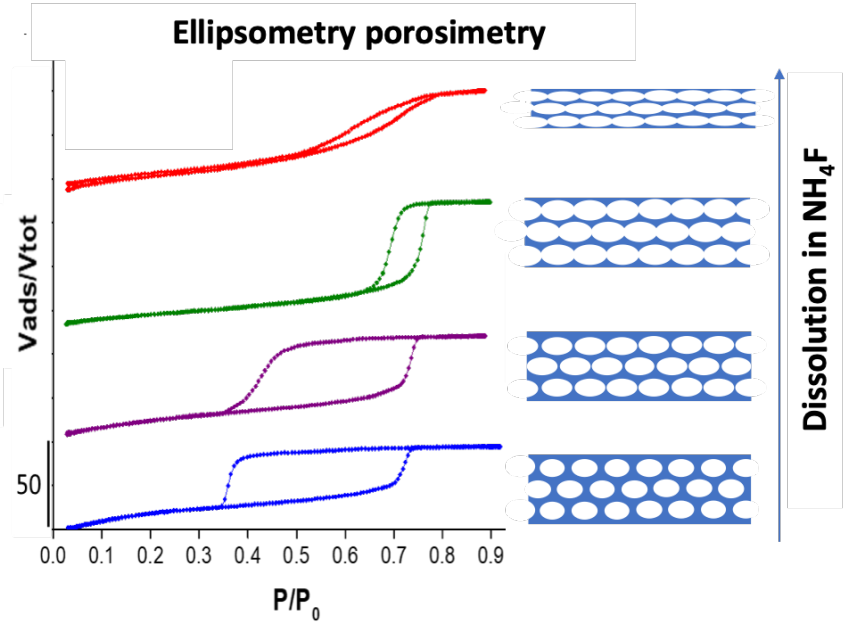

